\title{
JOÃO GILBERTO NOLL: \\ UM CONTEMPORÂNEO DE NOSSA VERTIGEM ESPECULAR
}

\author{
Chirley Domingues* \\ Dilma Beatriz Rocha Juliano**
}

RESUMO: Propõe-se indicar João Gilberto Noll como escritor fundamental para pensar a literatura do século XXI, especificamente no romance Lorde (2004). Usando uma linguagem indissociável entre prosa e poesia, o escritor é um contemporâneo ao criar narrativas à margem da exigência do espetáculo editorial e narrar "com o olhar fixo no seu tempo, para perceber não as luzes, mas o escuro" (AGAMBEN, 2009). A hipótese de contemporaneidade literária é a de que, com Lorde, é possível estabelecer uma aproximação com o desterramento, o desenlace, a provisoriedade, a melancolia que marca o nosso tempo - nosso e o da literatura. Longe do consumo, da submissão ao "vale-tudo" da felicidade como meta, o protagonista é frágil, inseguro e só. A contemporaneidade em João Gilberto Noll está numa literatura que não facilita, não é "produtiva", mas é potente ao confrontar, ameaçar e mostrar "identidades" em deterioração, nas imagens que o espelho que essa literatura retrata.

PALAVRAS-CHAVE: Contemporâneo; João Gilberto Noll; Lorde.

\section{Introdução}

Propõe-se indicar João Gilberto Noll, a partir de uma leitura do romance Lorde (2004), como autor indispensável para pensar a literatura do século XXI - um contemporâneo, no sentido dado ao termo por Giorgio Agamben, ou seja, um escritor "com o olhar fixo no seu tempo, para perceber não as luzes, mas o escuro”. (AGAMBEN, 2009, p. 62).

Em Lorde, o enigma do protagonista, que se revela sob a forma de um sintoma - a "solidão" -, pode ser lido em duplicidade: personagem e literatura. Se do personagem vem

\footnotetext{
* Doutora em Educação ela Universidade Federal de Santa Catarina (Ufsc) com doutorado sanduíche na Universidade de Évora (UE), em Portugal. Docente no Curso de Letras e Pedagogia da UNIVALI. Atua como professora e Pesquisadora do Programa de Pós-graduação em Ciências da Linguagem da Universidade do Sul de Santa Catarina (Unisul), na linha de pesquisa Linguagem e Cultura.

${ }^{* *}$ Doutora em Teoria Literária pela Universidade Federal de Santa Catarina (Ufsc). realizou estágio de pós-doutoramento no Centro de Estudos Comparatista, na Universidade de Lisboa. Atualmente é professora em tempo integral da Universidade do Sul de Santa Catarina (Unisul), atuando como professora e pesquisadora do Programa de Pós-graduação em Ciências da Linguagem, na linha de pesquisa Linguagem e Cultura.
} 
um esgotamento com as velhas formas do "eu", da literatura vem a recusa em corresponder à imposição de sucesso através do ingresso "alegre" no mercado com suas regras para um texto a ser consumido.

A hipótese de contemporaneidade literária que se levanta, então, é a de que, com Lorde, é possível perceber o desterramento, o desenlace, a provisoriedade, a melancolia que marca o contemporâneo - nosso e o da literatura. Se, no mercado das letras, o centro é a história a ser contada, a coerência entre as linhas narrativas e a verossimilhança que resenhe o texto do começo ao final, em Lorde (2004) o pensamento difuso do narrador personagem espraia como história, sem nenhuma preocupação aparente de seguimento, arredondamento ou desfecho. Os fios aparecem, têm continuidade ou desaparecem como fluxo do inconsciente, em associações de linguagem.

\section{A literatura em João Gilberto Noll}

Autor de textos inelidíveis entre prosa e poesia, sem uma estrutura preambular ou uma história conhecida para contar, as narrativas de Noll parecem passear à deriva pelas folhas de papel, onde "criaturas avulsas" se deslocam em delírios, em desejos, pelos espaços das cidades maiores e menores por onde o próprio escritor, biograficamente, andou. A crítica e professora de literatura, Florencia Garramuño (2014b), afirma que em João Gilberto Noll há uma proposital indiferenciação entre o pessoal e o público do escritor, marcas que já não fazem mais sentido de distinção na literatura contemporânea. Diferente das autobiografias pensadas no limite entre ficção e dados biográficos, para Garramuño, em Noll, trata-se de uma narrativa que extrapola os limites da literatura, em que o personagem é uma performance do escritor.

Em depoimento encontrado na página do Instituto Moreira Salles, ele próprio afirma sobre sua escrita:

Acredito na possibilidade de movimento através da própria linguagem. Sou um autor da linguagem, mas não um autor formalista. Não estou para fazer floreios estruturais, só acho que o exercício da linguagem tem a forma estruturante de nos levar ao significado, que possa ter num romance, num conto, numa novela. O significado não é prévio, não antecede ao exercício da linguagem. É um a posteriori, 
um resultado desse exercício, dessa flexão, mesmo, entre você e a linguagem, entre você e o instante. (NOLL. s/d)

Refletindo sobre seu processo de criação, Noll alega que a ação em suas narrativas se dá pela linguagem, pelo trabalho que incessantemente empreende com as palavras, fazendo com que ali a narrativa se desenrole. Ele diz:

\begin{abstract}
Sou um escritor da linguagem, pelo método com o qual escrevo fica claro isso. Tento captar a realidade através do que a linguagem me indica. [...]. Realmente o que vai puxar, me arrastar, me movimentar em direção à ação do livro não é uma ideia de conteúdo prévio, mas é aquilo que a linguagem vai abrindo para mim. Como se realmente a linguagem fosse um exercício desejante de ação. (NOLL. s/d)
\end{abstract}

Em sua literatura, a ação se dá pelo trabalho com as palavras, em oposição a uma das marcas de sucesso das mercadorias literárias em que a história é o centro da narrativa. É a linguagem como fio que conduz autor e leitor pelo tecido narrado. Os fatos são narrativos e se desenvolvem no interior dos personagens. Neste sentido, os fatos são pensamentos que ligam o dentro e o fora dos sujeitos narrados, mas sem distinção entre os espaços, numa espécie de "fantasmagoria do real". (GARRAMUÑO, 2014a, p. 18).

Pensar sobre a literatura, sobre a sua escrita, seu estar no mundo das linguagens, são temas na ficção de Noll e, não raras vezes, um escritor é personagem, indistintamente o narrador não é diferente dele próprio. (GARRAMUÑO, 2014a). Flora Süssekind , pensando sobre o teatro de Noll, assinala três aspectos identificados em seus textos que reincidem no romance Lorde: "duplicação, de um lado; esfacelamento, de outro"; "uso reiterado do monólogo, de uma primeira pessoa narrativa cujo trânsito incessante acentua ainda mais sua auto-exposição (sic)"; e, "tensão entre a presença dominante de um narrador que é sujeito e objeto dos relatos, e a instabilidade - 'sou fulano, sicrano, beltrano, ninguém' - , que o força a um trânsito constante [...]”. (SÜSSEKIND, 1998, p. 55 e 57)

Assim é em Lorde (2004). O protagonista é um escritor brasileiro que, vivendo um profundo cansaço, se coloca em vertiginosa reflexão metafísica entre um “eu” em transformação e um mundo de enunciados imperativos para sujeitos jovens, financeiramente 
bem-sucedidos, felizes, seguros de si. Identificado com os vencidos, o escritor personagem, que apesar "de seus livros muitas vezes serem bem recebidos pela crítica quando não pelo público" (NOLL, 2004, p. 20), não está em condições financeiras de sobrevivência; ele "não tem escolha" e aceita o convite para ir a Londres, numa "missão"4 da qual nada sabe e até duvida que exista.

O filósofo Byung-Chul Han, no ensaio Sociedade do cansaço (2015), reitera o fim da sociedade disciplinar assim como Deleuze já o havia feito no Post-scriptum. sobre as sociedades de controle (1992). Embora denomine o agora por "sociedade do desempenho", Han se aproxima da noção deleuzeana ao afirmar:

A sociedade do século XXI não é mais a sociedade disciplinar, mas uma sociedade de desempenho. Também seus habitantes não se chamam mais "sujeitos da obediência", mas sujeitos de desempenho e produção. [...] A sociedade disciplinar ainda está dominada pelo não. Sua negatividade gera loucos e delinquentes. A sociedade do desempenho, ao contrário, produz depressivos e fracassados. (HAN, 2015, p. 23-24)

Se em Foucault se pode ler o disciplinamento dos corpos como tecnologia de poder executadas de fora para dentro, em Deleuze a sociedade já está controlada pela a introjeção dos deveres e poderes, sem necessidade de comando externo; as subjetividades, já atravessadas pela disciplina, respondem com "sujeitos da obediência". Com Byung-Chul Han, as subjetividades controladas e controladoras se movem pelo cansaço, pelo desalento e pela depressão como falência da vontade, mas, paradoxalmente, premidos pelo imperativo do desempenho: empreender e reinventar de si mesmo, almejar o sucesso financeiro.

\footnotetext{
${ }^{4}$ A literatura vinculada a ideia de "missão" não é nova. No entanto, é retomada pela crítica Leyla Perrone Moisés para pensar a literatura do século XXI, relacionando os escritores da "alta modernidade" aos românticos do século XIX. Ela se refere à "missão" em relação à figura heroica dos escritores ao assumirem a literatura como vocação, uma posição de apego à "uma literatura autotélica e altiva, oposta à sociedade burguesa" (PERRONE-MOISÉS, 2016, p. 125). Em Lorde a "missão" é ironicamente referida como algo que o personagem aceitara para ganhar uma graninha extra". O leitor termina a leitura duvidando, com o personagem, que a "missão" tenha efetivamente existido como proposta ou não passara de uma ilusão. Nesse sentido, na literatura de Noll não há a retomada heroica do escritor como tendência (vinda dos românticos) apontada pela crítica como uma das mutações da literatura para o século XXI.
} 
Em Lorde, são nítidos o cansaço e a desconfiança em seu próprio desempenho; descrente da missão/convite, o escritor imagina palestras e encontros com estudantes que justificassem sua estada em Londres, mas nada acontece. Ele sabe que não cumpre o desempenho esperado de um escritor, um sujeito de sucesso:

Sim, disfarçara nas entrevistas ao lançar meu derradeiro livro, sim, vou passar uma temporada em Londres, representarei o Brasil, darei o melhor de mim - o quá-quá-quá surfava na minha traquéia (sic) sem poder sair, entende? (NOLL, 2004, p. 11)

Neste sentido, o escritor personagem se aliena na sociedade do desempenho sem, no entanto, “cancelar o dever" (HAN, 2015, p. 25) de desempenhar, num indecidível entre sucesso e fracasso. Sem poder corresponder ao imperativo de sucesso, apesar de reconhecê-lo em circulação, ele é a própria denúncia do discurso vazio que não suporta a angústia do esvaziamento - não há o que prometer senão o vazio.

Eu pediria uma conferência, apenas uma, mostraria a ele e a toda a audiência como estava atualizado com todas as pulsões brasileiras o que era mentira, sei, pois já não lembrava direito de onde tinha vindo, o Brasil naquelas alturas se insinuava em pura abstração. (NOLL, 2004, p. 29)

Claramente, o escritor indisciplinado indica o limite com o qual se debate - "o que causa a depressão do esgotamento não é o imperativo de obedecer apenas a si mesmo, mas a pressão de desempenho”. (HAN, 2015, p. 27 - grifo do autor).

A contemporaneidade literária em João Gilberto Noll está, assim, numa ficção que não facilita, não é "produtiva", ao contrário, é potente ao confrontar, ameaçar e mostrar “identidades” em deterioração, nas imagens que o espelho que essa literatura refrata.

\section{Contemporaneidade: ao invés das luzes, o escuro é o centro}

Ao se perguntar sobre o significado de ser contemporâneo, Giorgio Agamben desenha uma noção importante para o pensamento crítico que se arma por constelações - 
coincidências e disjunções -, noção que se situa longe das cronologias regidas pelas linearidades, que tanto controlaram os caminhos literários das genealogias e historiografias universalizantes. Para ele,

pertence verdadeiramente ao seu tempo, é verdadeiramente contemporâneo, aquele que não coincide perfeitamente com este, nem está adequado às suas pretensões e é, portanto, nesse sentido, inatual; mas, exatamente por isso, exatamente através desse deslocamento e desse anacronismo, ele é capaz, mais do que os outros, de perceber e apreender o seu tempo. (AGAMBEN, 2009, p. 58-59)

Em Lorde, o personagem escritor, tentando coincidir com o comum de ser escritor, estar em Londres, andar nas ruas tal e qual um homem da multidão, assinala a impossibilidade de dissolver-se:

Se conseguisse ser esse homem que me pulsava ainda mais, tentaria de todas as maneiras me manter em Londres, agora, sim, e escreveria então uma outra história - publicaria em inglês essa minha transformação num alienígena, essa transformação que acabaria mórbida se eu não lhe desse um rumo franco. (NOLL, 2004, p. 32)

A narrativa vai sendo tecida, de parágrafo a parágrafo, na aflitiva ambivalência entre o corresponder aos índices esperados pela "sociedade de desempenho" - "O homem certo, eficaz, translúcido, [...] eu, esse homem pacato de que já falei, feito para não ter vaidades, para desconhecer até suas feições" (NOLL, 2004, p. 24) - e sua própria impossibilidade de "coincidir perfeitamente": "Tinha para mim que os meus passos se mostravam ágeis, irmanados de uma forma estranha ao ritmo veloz da multidão”. (NOLL, 2004, p. 33). Caminha como uma escrita que "falha" em ser produtiva, uma literatura com as vértebras fraturadas", e exatamente aí fala de nós, seus contemporâneos. Ele não coincide perfeitamente com o

\footnotetext{
${ }^{5}$ Refere-se ao poema russo "O século", de Osip Mandel'stam, de 1923; precisamente na estrofe: "Meu século, minha fera, quem poderá/olhar-te dentro dos olhos/e soldar com o seu sangue/as vértebras de dois séculos?" (AGAMBEN, 2009, p. 60)
} 
tempo dos textos perecíveis e que, portanto, precisam ser repostos intensa e rapidamente. Essa não é a sua produção.

Não por oposição, mas na contraface do controle, a forma escritor/personagem (re)afirma o poder da escritura/literatura em seguir se transformando e subverte a contenção: "Eles tinham me internado por uma razão que eu desconhecia. Eu a usaria para nascer". (NOLL, 2004, p. 35)

Neste sentido, Noll opera como o poeta descrito por Agamben (2009, p. 60): “O poeta, enquanto contemporâneo, é essa fratura, é aquilo que impede o tempo de comporse e, ao mesmo tempo, o sangue que deve suturar a quebra.”. O personagem segue em gesto de sutura:

Dessa vez me impulsionei com minha própria, recentíssima desordem interna - fui em frente: me vesti, passei pelo corredor do hotel com passos decididos de um novo homem. Lá embaixo Liverpoll era a mesma. Só que agora à luz do sol. (NOLL. 2004, p. 110)

Especialmente em Lorde, o que se pretende afirmar é que a contemporaneidade em Noll está na impropriedade dúplice: personagem e literatura - não são próprios de um gênero, escancaram a obsolescência das fórmulas (romance e identidade, por exemplo) sem decretar seu fim, se constroem na descontinuidade, na instabilidade. Literaturas que, nas palavras de Garramuño (2014a, p. 13-14), “o que as define não é tanto sua brevidade, mas o fato de elas não chegarem a articular-se num lugar específico, a sustentar-se numa identidade, a procurar ou achar um abrigo que as proteja".

\section{A identidade, o espelho}

Porque longe do consumo, da submissão ao "vale-tudo" da felicidade como meta, o protagonista tem a aparência de fragilidade, de insegurança e do sofrimento; em seus deslocamentos pela cidade ele se transforma muitas vezes no decorrer da narrativa, movendo-nos em aproximação com ele pela inconsistência de nossas próprias identificações. Portador melancólico de experiências literárias que o aproximam de um "alienígena”, teme transformar-se num personagem de livro de "baixa espionagem". Mais uma dúvida: ele 
mergulha na multidão anônima inglesa, “...um daqueles autores imigrantes, sem nacionalidade precisa..." (NOLL, 2004, p. 33), ou deve transformar-se no dândi que tanto desejara ser quando ainda em Porto Alegre? Numa clara alusão ao alto e ao baixo da infrutífera classificação artística, o protagonista/autor segue alheio aos estímulos externos, ele está mais próximo do pensamento sobre si próprio do que dos discursos normativos que vai descartando ao longo do romance. A referência aristocrática que intitula o romance, por exemplo, se revela irônica, uma vez que qualquer possibilidade nobiliária, ou de opulência aristocrática do escritor convidado, vai se desvanecendo na narrativa pela descrença naquilo que fora fazer na Inglaterra e nele próprio como portador de algo a dizer - “...eu não sofria exatamente de credulidade, vivera até o dia da viagem me retorcendo em dúvidas com relação às intenções dele, desse tal inglês[...]" (NOLL, 2004, p. 10).

Num redesenho constante "do nosso rosto incerto" a olhar-se "no espelho do mundo" (PELBART, 2000, p. 11) e só ver subjetividades em trânsito está o protagonista estamos nós - por um fio.

Rondei pelo apartamento, a começar pelo banheiro, à procura de um espelho. Não havia. [...]. Não era por nada, queria me ver depois da viagem, ver se eu ainda era o mesmo, se este que tinha se adonado de uma casa nos subúrbios de Londres tinha remoçado com a mudança, trazia a pele oleosa, seca, ou com sérias marcas que lhe facultavam desistir do andamento daquela carruagem [...]. (NOLL, 2004, p. 23)

Sem gratuidade, o espelho vai servindo para mostrar o envelhecimento, os anos passados que produzem o desconhecimento de si mesmo - "Passava a mão pela face como que a limpá-la do tempo acumulado; ah, cogitava estar vivendo um cansaço extremo e por isso a vista me castigava despindo o meu próprio rosto" (NOLL, 2004, p. 25).

O protagonista escritor sai do Brasil, “alguém todo preparado para atravessar o Atlântico de uma hora para a outra, sem ter nada o que deixar que carecesse da sua presença” - (NOLL, 2004, p. 10), e vai para Londres, onde a percepção de desterritorialização das identidades é tematizada e denunciada teórica e criticamente desde os anos 50/60, do 
século XX, pelos estudos culturais. " "Eu tinha escrito os meus livros, certo, mas até que ponto eles revelavam alguma coisa que já não fosse doméstica a qualquer um nascido, criado e morador perene daquele país aonde agora eu chegava sem adivinhar pra quê?” (NOLL, 2004, p. 16)

Da crítica e da ficção vem o conhecimento da falta de inteireza e da instabilidade das "identidades", tal qual fomos induzidos a imaginá-las a partir das forças de controle e de disciplinamento. Não sem assombro, se constata o impalpável das subjetividades, que parecem perder uma espessura que aparentavam ter e que permitiriam um falar de si mais duradouro, mais estabilizado. "Este que eu começaria a desconhecer" (NOLL, 2004, p. 11).

O espelho comprado pelo personagem é metáfora produtiva para se compreender a subjetividade como "plenamente fabricada, produzida, moldada, modulada - e também, por que não, a partir daí, automodulável (sic)" (PELBART, 2000, p. 12). "Encontrei um prego na parede da banheira para pendurar o espelho. De modo que eu tinha de entrar nela para olhar quem era esse senhor aqui. [...] Mas agora já não me reconhecia, de tantos anos passados" (NOLL, 2004, p. 25). Para logo em seguida,

Sim, ali achei uma loja de cosméticos. Eu precisava perder o medo, entrar, pedir algum produto que me amenizasse as rugas, as marcas fundas entre o pouso das narinas e as pontas dos lábios. Eu vivia agora, enfim, em outro país, pouco importando se zombassem de $\operatorname{mim} . . .(N O L L, 2004$, p. 25)

\footnotetext{
${ }^{6}$ Emblemático nesta discussão é Stuart Hall ao colocar em questão "velhas identidades" com as quais se distribuíam papéis a partir de dicotomias: feminino/masculino, do campo/da cidade, incultos/cultos, brancos/negros, e tantas outras. Hall mostra como estas "identidades" passam pela "modernidade tardia" e sofrem seus efeitos a partir da circulação global do capitalismo econômico; chegando na "pós-modernidade" à desessencialização e às definições provisórias do que ainda se poderia chamar de identidades. Nas suas palavras, "[...], a identidade é realmente algo formado, ao longo do tempo, através de processos inconscientes, e não algo inato, existente na consciência no momento do nascimento. Existe sempre algo 'imaginário' ou fantasiado sobre sua unidade. Ela permanece sempre incompleta, está sempre 'em processo', sempre 'sendo formada". (HALL, Stuart. A identidade cultural na pós-modernidade. 7. ed., Trad. Tomaz Tadeu da Silva, Guacira Lopes Louro. Rio de Janeiro: DP\&A, 2002, p. 38)
} 
No entendimento de Peter Pál Pelbart (2000), em referência a Michel Foucault, não há o que se descobrir nas subjetividades contemporâneos, a não ser a necessidade de inventá-las. No entanto, em Lorde, desde a chegada ao aeroporto até adormecer no cemitério, o que se tem é um sujeito em duplo movimento: a busca por desvendar seu próprio enigma, do qual a solidão é o sintoma (como já dito anteriormente), e a constatação da impossibilidade de respostas, que se revela nas suas reinvenções ou dúvidas sobre sua própria capacidade de fazê-lo. "Ninguém mais me reconheceria, já que tinha feito uma reforma em cima de alguém que eu mesmo começava seriamente a estranhar" (NOLL, 2004, p. 27). E segue,

[...] se não o reinventasse dentro de mim e me pusesse a perder a mim próprio, sendo doravante ele em outro, neste mesmo que me acostumara a nomear de eu, mas que se mostrava dissolvido ultimamente, [...], ora, sem isso não calcularia como prosseguir. (NOLL, 2004, p. 27-28)

O personagem caminha, física e imaginariamente, entre a confirmação de um "eu" em dissolução constante e a inevitável invenção de si para poder prosseguir. Ele diz:

Alguém com quem podemos conviver por alguns minutos sem peso ou infortúnio, mas que logo podemos deixar de lado à procura de uma outra identidade que teima em nos escapar. Eu era um dândi, agora eu compreendia muito bem, e nenhuma cidade do mundo poderia me constituir tão bem quanto aquela em que por acaso eu vivia naquele instante. (NOLL, 2004, p. 29)

\section{E por fim....}

A imagem especular do personagem escritor permite que se leia em dúplice a ação da linguagem em reflexões pessoais e literárias, ambas em trânsito. Ele sabe, desde o Brasil, da impossibilidade de continuar o mesmo e com a mesma literatura. A maquiagem e o tingimento do cabelo acenam como tentativas de corresponder à sociedade do espetáculo; investimento que dura pouco: as tintas escorrem e o espelho é virado para a parede, gesto que indica que já não interessa mais a sua imagem nele refletida; as imagens espetaculares 
ficam como tentativas abandonadas no decorrer da narrativa. Se por um momento a maquiagem e a tinta no cabelo serviram para atenuar o envelhecimento, ao deslizarem pelo rosto abaixo ratificam tratar-se de uma frágil fachada, novamente no duplo da linguagem.

Andava metido num romance de baixa espionagem e agora inoculado de alguma substância que me faria mais submisso a eles - eu, com minha mente turva, e sobretudo por isso, lhes daria a chave que não tinha condições de prever. (NOLL, 2004, p. 36)

Tal qual a solidão de seu personagem, a literatura de Noll carece de pertencimento, de linhagem, como insiste em buscar/assinalar o mercado editorial em relação a ficção “autoral". O que se pode apontar, a partir de Garramuño (2014a), é que o autor ensaia um outro tipo de pertencimento, aquele que como "norma” transborda os limites do literário, aquele em que a própria literatura é posta em questão. Ela afirma que,

Uma desapropriação da especificidade, portanto, caracterizaria essas práticas do não pertencimento. Se propuser que se caracterizasse o efeito dessa aposta no inespecífico como a elaboração de práticas de não pertencimento mais do que como novos modos de pertencimento, é porque me parece que nesse movimento de invenção do comum como inespecífico e impessoal - ainda que único - elas nos estão propondo outros modos de organizar nossos relatos, e, por que não?, também nossas comunidades. (GARRAMUÑO, 2014a, p. 29)

As tentativas de atribuição de sentido não definem, não há crítica que possa domar a literatura em Noll - são todas significações provisórias, frágeis, frouxas como o "eu” do protagonista, uma “inespecificidade na estética contemporânea” (GARRAMUÑO, 2014a). Como as identidades, trata-se de uma literatura movente, fugidia, “explosões multitudinárias que denunciam os modos de produção de sentido e valor que caducaram" (PELBART, 2013, p. 15). Esta é a literatura que resiste, no escuro de seu tempo, longe dos holofotes do espetáculo editorial.

Deitei sobre a grama seca com a cabeça sobre ele [sobretudo dobrado]. Eu precisava adormecer. Ver se sonharia o sonho do outro 
de quem jurava ter ainda sobras do sêmen na mão. Seria prova irrefutável do que eu aprenderia a aceitar...E adormeci... (NOLL, 2004, p. 111)

Não cabe na arte literária a repetição, a fórmula de sucesso, em Noll nada soa como o mesmo. Trata-se sempre de uma literatura em luta por nascer a todo momento e a cada vez. O personagem escritor aparece em dissolução, perdendo a forma, sujo e insone, mas sempre reivindicando para si um desejo, uma relação com o(s) outro(s). Um aberto.

Neste sentido, a "solidão" que diz portar o personagem é, sim, "o escuro do seu tempo como algo que lhe concerne e não cessa de interpelá-lo, algo que, mais do que toda a luz, dirige-se direta e singularmente a ele" (AGAMBEN, 2009, p. 64). Diz o personagem: "Eu era tão sozinho quanto um homem que vaga por entre uma floresta imprecisa, misto de árvores e sons de animais noturnos" (NOLL, 2004, p. 94).

Não se trata, portanto, de uma "solidão negativa", daquelas que "são socialmente produzidas, pelo descaso do Estado, pela exclusão dos velhos, dos deficientes físicos ou mentais, dos desempregados, dos inempregáveis etc.” (PELBART, 2000, p. 19). Não há desistência em Lorde, mas reinvenção da subjetividade e da literatura:

E pelas aléias (sic) comecei a caminhar. As aves marinhas gritavam ao fundo, mas não dava ainda para divisá-las. [...] Tudo ainda sem folhas, na aridez do inverno. Pulei um muro de pedras em ruínas, andei, andei me desvencilhando de galhos espinhentos. Como se de repente numa floresta encantada, às vésperas da primavera, eu fosse ter o meu lugar. (NOLL, 2004, p. 111)

Noll estende para mais distante as linhas das potências narrativas, saltando sobre as ruínas, com a

[...] solidão positiva, afirmativa, disjuntiva, [que] constituiria numa maneira de resistir a um socialitarismo despótico, de desafiar a tirania das trocas produtivas e da circulação social. Aí se esboça, às vezes, uma espécie de comunidade dos desiguais, máquinas celibatárias, subjetividades parciais, onde o excesso e a dispersão inumana não se apagam por uma reinscrição social obrigatória. (PELBART, 2000, p. 19-20) 
Noll se inscreve no presente e assume, como escritor, "o compromisso que está em questão na contemporaneidade: é, no tempo cronológico, algo que urge dentro deste e que o transforma” (AGAMBEN, 2009, p. 65).

\section{JOÃO GILBERTO NOLL: A CONTEMPORARY OF OUR SPECULAR VERTIGO}

ABSTRACT: This study aims to indicate João Gilberto Noll as a fundamental writer to think about the 21 st century literature, specifically in the novel Lorde (2004). Using an indissociable language between prose and poetry, the writer is a contemporary in creating narratives at the margins of the demand of the editorial scene and narrating with "his gaze on his own time so as to perceive not its light but rather its darkness" (Agamben, 2009). The hypothesis of literary contemporaneity is that, with Lorde, it is possible to establish an approximation with the exile, the outcome, the transience, the melancholy of our times - as well as that of literature. Far from consumption, from submission to the "no holds barred" of happiness as a goal, the protagonist is fragile, insecure and lonely. The contemporaneity in João Gilberto Noll is in a literature that does not make things easy, is not "productive", but is potent in confronting, threatening and showing deteriorating "identities" in the images of a mirror that this literature portrays.

KEYWORDS: Contemporary; João Gilberto Noll; Lorde.

\section{REFERÊNCIAS}

AGAMBEN, Giorgio. O que é o contemporâneo? e outros ensaios. Trad. Vinícius Nicastro Honesko. Chapecó (SC): Argos, 2009.

DELEUZE, G. Post-scriptum. Sobre as sociedades de controle. Trad. Peter Pál Pelbart. São Paulo: Editora 34, 1992. Disponível em: http://www.somaterapia.com.br/wp/wp-content/uploads/2013/05/Deleuze-Post-scriptum-sobre-sociedades-de-controle.pdf Acessado em 02/02/2019

GARRAMUÑO, Florencia. Frutos estranhos. Sobre a inespecificidade na estética contemporânea. Trad. Carlos Nougué. Rio de Janeiro: Rocco, 2014a.

. Formas do não pertencimento na estética contemporânea. Curso intensivo ministrado na Universidade do Sul de Santa Catarina (UNISUL), em abril de 2014, 2014b.

HAN, Byung-Chul. Sociedade do cansaço. Trad. Enio Paulo Gianchini. Petrópolis (RJ): Vozes, 2015.

NOLL, João Gilberto. Lorde. São Paulo: Francis, 2004.

. O avesso do conhecimento. Instituto Moreira Salles. s/d. Disponível em:

<https://ims.com.br/titular-colecao/joao-gilberto-noll/> Acessado em: 02/07/2018. 
PELBART, Peter Pall. $A$ vertigem por um fio. Políticas da subjetividade contemporânea. São Paulo: Iluminuras, 2000. . O avesso do niilismo. Cartografias do esgotamento. São Paulo: n-1 Edições, 2013.

PERRONE-MOISÉS, Leyla. Mutacõoes da literatura no século XXI. São Paulo: Companhia das Letras, 2016.

SÜSSEKIND, Flora. A voz e a série. Rio de Janeiro: Sette Letras; Belo Horizonte: UFMG, 1998.

Recebido em: 06/05/2020.

Aprovado em: 30/05/2020. 